\title{
Prefrontal Glutamate Release into the Core of the Nucleus Accumbens Mediates Cocaine-Induced Reinstatement of Drug-Seeking Behavior
}

\author{
Krista McFarland, Christopher C. Lapish, and Peter W. Kalivas \\ Department of Physiology ad Neuroscience, Medical University of South Carolina, Charleston, South Carolina 29425
}

\begin{abstract}
The relative contributions of glutamate and dopamine within the nucleus accumbens to cocaine-induced reinstatement of drug-seeking behavior were assessed. When extinguished cocaine self-administration behavior was reinstated by a cocaine-priming injection, extracellular levels of both dopamine and glutamate were elevated in the nucleus accumbens. However, when yoked cocaine or saline control subjects were administered a cocaine prime, only dopamine levels were elevated. Thus, glutamate increased only when animals reinstated lever pressing, whereas dopamine increased regardless of behavior. The increase in glutamate was not accounted for simply by the act of lever pressing itself, because the cocaine self-administration group still demonstrated elevated glutamate when the levers were withdrawn from the operant chamber. Moreover, reinstatement of lever pressing for food did not elevate extracellular glutamate, indicating that increased glutamate initiated responding selectively for a drug reinforcement. The source of glutamate was shown to be glutamatergic afferents from the prefrontal cortex because inhibiting prefrontal cortical glutamatergic neurons that project to the accumbens prevented the rise in glutamate. Together, these data demonstrate that activation of a glutamatergic projection from the prefrontal cortex to the nucleus accumbens underlies cocaine-primed reinstatement of drug-seeking behavior.
\end{abstract}

Key words: dopamine; glutamate; reinstatement; nucleus accumbens; medial prefrontal cortex; self-administration; cocaine

\section{Introduction}

One of the defining characteristics of cocaine (COC) addiction is repeated cycles of drug use followed by abstinence. Thus, the biggest challenge to successful treatment of cocaine addiction is preventing craving and relapse. Neuroimaging studies in addicts demonstrate that metabolic activation of the prefrontal cortex is associated with craving for cocaine (Volkow et al., 1999; Kilts et al., 2001). Despite this well documented involvement of the prefrontal cortex in human craving, most animal studies have centered on the nucleus accumbens because it receives a major dopamine projection from the ventral tegmental area (Fallon and Moore, 1978) that is critical for the learning and maintenance of goal-directed responding, including drug-seeking behavior (Koob and Swerdlow, 1988; Ettenberg, 1989).

Notably, many long-term adaptations resulting from repeated drug exposure manifest as presynaptic and postsynaptic changes in dopamine and glutamate transmission within the nucleus accumbens. For example, there is an enduring electrophysiological supersensitivity of $D_{1}$ dopamine receptors (Henry and White, $1991)$ and accompanying increases in protein kinase A signaling (Zhang et al., 2002), as well as increased releasability of presynaptic dopamine that depends on calcium/calmodulin-dependent protein kinase II signaling (Pierce and Kalivas, 1997; Gnegy, 2000). Additionally, basal extracellular levels of accumbens glu-

Received Dec. 12, 2002; revised Jan. 29, 2003; accepted Feb. 5, 2003.

This research was supported in part by United States Public Health Service Grants DA12513, MH40817, and DA03906 and Postdoctoral National Research Service Award DA05978 (K.M.). We thank Susan Brie Davidge and Russell Chapin for their outstanding technical assistance.

Correspondence should be addressed to Krista McFarland, Department of Physiology and Neuroscience, 173 Ashley Avenue, Medical University of South Carolina, Charleston, SC 29425. E-mail: mcfarlk@musc.edu. Copyright $\odot 2003$ Society for Neuroscience $\quad 0270-6474 / 03 / 233531-07 \$ 15.00 / 0$ tamate are decreased (Pierce et al., 1996), whereas there is increased glutamate in response to a cocaine challenge (Pierce et al., 1996; Reid and Berger, 1996). Furthermore, electrophysiological and neurochemical experiments find long-term decreases in signaling through AMPA (Thomas et al., 2001; Beurrier and Malenka, 2002) and metabotropic glutamate receptors (mGluRs) (Swanson et al., 2001; Xi et al., 2002) after repeated cocaine administration. Together, these data demonstrate that enduring changes in either glutamate or dopamine transmission in the nucleus accumbens produced by repeated cocaine administration could contribute to the enduring expression of craving and relapse in addicts.

Consistent with the notion that the nucleus accumbens plays a central role in mediating renewed responding after drug abstinence is the finding that reversible inactivation of the core of the nucleus accumbens (NAcore) blocks cocaine-induced reinstatement (McFarland and Kalivas, 2001). Studies implicating dopamine transmission in reinstatement include demonstrations that systemic pretreatment with dopamine receptor antagonists block, whereas direct and indirect dopamine agonists facilitate reinstatement of cocaine-seeking behavior (De Vries et al., 1999, 2002). Also, infusion of dopamine or cocaine directly into the nucleus accumbens reinstates cocaine-seeking behavior (Cornish and Kalivas, 2000; Park et al., 2002). However, infusion of $D_{1} / D_{2}$ dopamine receptor antagonist directly into the NAcore fails to block cocaine-primed reinstatement (McFarland and Kalivas, 2001) Instead, infusion of AMPA glutamate receptor antagonist prevents reinstatement by a cocaine prime (Cornish and Kalivas, 2000), and AMPA receptor agonists elicit reinstatement responding (Cornish et al., 1999).

The goal of the present study was to simultaneously assess the 
involvement of dopaminergic and glutamatergic mechanisms within the accumbens to cocaine-induced reinstatement of drugseeking behavior. Subjects with their cocaine self-administration (SA) behavior extinguished were tested for their propensity to reinstate responding after cocaine challenge. During tests for reinstatement in vivo microdialysis was performed, and the levels of extracellular glutamate and dopamine were measured.

\section{Materials and Methods}

Animal housing and surgery. All experiments were conducted in accordance with the National Institutes of Health Guidelines for the Care and Use of Laboratory Animals, and the Institutional Animal Care and Use Committee at the Medical University of South Carolina approved all procedures. The subjects were 62 male Sprague Dawley rats, purchased from Charles River Laboratories (Indianapolis, IN). They were housed in an Association for the Assessment and Accreditation of Laboratory Animal Care-approved facility, in a temperature-controlled room $\left(23^{\circ} \mathrm{C}\right)$, maintained on a $12 \mathrm{hr}$ reverse light/dark cycle (lights on 7:00 P.M.). On arrival, subjects were weighed and handled daily for 1 week to assess their health and allow them to acclimate to handling procedures. Animals were given ad libitum access to food (Purina Rat Chow; Purina Mills, St. Louis, MO) until $7 \mathrm{~d}$ after surgery, when they received a 20 gm daily ration of food for the remainder of the experiment. This regimen aided in the acquisition of the lever-press response while allowing them to gain weight throughout the course of the experiment.

One week after arrival, rats were anesthetized with ketamine $\mathrm{HCl}$ (87.5 $\mathrm{mg} / \mathrm{kg}$ Ketaset; Fort Dodge Animal Health, Fort Dodge, IA) and xylazine ( $5 \mathrm{mg} / \mathrm{kg}$ Rompum; Bayer, Shawnee Mission, KS) and implanted with intravenous catheters, microdialysis guide cannulas (26 gauge, cut to 11 $\mathrm{mm}$ below the pedestal; Plastics One, Roanoak, VA) aimed at the NAcore, and bilateral microinfusion guide cannulas (30 gauge, cut to 14 $\mathrm{mm}$; Small Parts, Logansport, IN) aimed at the dorsal prefrontal cortex (PFCd) (corresponding to the transition between the prelimbic and anterior cingulated cortices). Coordinates were determined according to the atlas of Paxinos and Watson (1998): NAcore (anteroposterior, + 1.2 $\mathrm{mm}$; mediolateral, $\pm 2.5 \mathrm{~mm}$ at and angle of $6^{\circ}$ from vertical; dorsoventral, $-4.7 \mathrm{~mm}$ relative to bregma) and PFCd (anteroposterior, $+3.0 \mathrm{~mm}$; mediolateral, $\pm 0.7 \mathrm{~mm}$; dorsoventral, $-2.2 \mathrm{~mm}$ relative to bregma). For cannula implantation, the skull was exposed, and holes were drilled at the target locations. Additional holes were drilled peripheral to the target locations, and jewelers screws were inserted to serve as anchors. The cannulas were lowered to the desired location, and then cannulas and screws were embedded in dental acrylic to fasten them to the skull. Metal obdurators ( 33 gauge; Small Parts) were inserted to extend $0.5 \mathrm{~mm}$ beyond the tip of the injection cannulas to prevent their obstruction by debris.

For catheter implantation, a guide cannula (C313G; Plastics One) attached to SILASTIC tubing ( 0.025 inner diameter; 0.047 outer diameter; VWR Scientific, West Chester, PA) and Marlex mesh (Allegiance, McGaw Park, IL) via dental cement was inserted subcutaneously between the shoulder blades, with the guide cannula externalized through a dermal biopsy hole $(3 \mathrm{~mm})$. The other end of the SILASTIC tubing was threaded subcutaneously to the jugular vein. After the vein was isolated, the tubing was inserted $2.7-3.0 \mathrm{~cm}$ and secured in place with sutures to the underlying muscle tissue. Subjects remained on a heating pad, closely monitored, until they were fully conscious. The catheter was flushed daily with (1) heparinized saline $(0.2 \mathrm{ml}$ of $100 \mathrm{IU})$ to help maintain catheter patency and (2) cefazolin antibiotic $(0.2 \mathrm{ml}$ of $0.1 \mathrm{gm} / \mathrm{ml})$ to help protect against infection.

Self-administration and extinction procedures. Behavioral training began $7 \mathrm{~d}$ after surgery. All training and testing was conducted in standard operant chambers fitted with two retractable levers (ENV-008; Med Associates, Georgia, VT). The first step in behavioral training was acquisition of the lever-press response, in which subjects were trained in a single $15 \mathrm{hr}$ training session to press a lever on a fixed ratio 1 (FR-1) schedule of reinforcement for one $45 \mathrm{mg}$ food pellet (Noyes, Lancaster, NH). The next day, the reinforcer was switched to a cocaine- $\mathrm{HCl}$ solution $(0.25$ $\mathrm{mg} / \mathrm{kg}$ ). Presses on the active lever now resulted in an intravenous infu- sion of cocaine (over $4 \mathrm{sec}$ ), whereas presses on the inactive lever had no programmed consequences. Cocaine reinforcement was delivered on a modified FR-1 schedule such that each infusion of cocaine was accompanied by illumination of a stimulus over the lever and a $20 \mathrm{sec}$ timeout when active lever presses were counted but did not result in reinforcer delivery. After $20 \mathrm{sec}$, the stimulus light was extinguished and the first lever press again resulted in cocaine delivery. Daily training sessions lasted $2 \mathrm{hr}$ or until a subject earned 200 cocaine infusions, whichever came first. Subjects remained in cocaine self-administration training until they met an acquisition criterion that required the average presses on the active lever over 3 consecutive training days to vary by $<10 \%$.

Once subjects met the acquisition criterion, extinction procedures were instituted on the following day. During extinction training, presses on the active lever resulted in infusions of saline (SAL) $(0.9 \%$ saline over $4 \mathrm{sec}$ ) instead of cocaine. All other aspects of training remained the same. Subjects remained in behavioral extinction until responding on the active lever averaged $10 \%$ or less of active lever pressing during maintenance for 3 consecutive days. The day after meeting this criterion, subjects were returned to the operant chambers for probing and reinstatement testing, as described below.

Yoked control subjects. Some rats served as yoked control subjects for the self-administering rats. Each yoked subject was paired with a rat that self-administered cocaine and received either intravenous infusions of cocaine (cocaine-yoked rats, $0.25 \mathrm{mg} / \mathrm{kg}$ over $4 \mathrm{sec}$ ) or saline (salineyoked rats, $0.9 \%$ ) in the same temporal pattern as that self-administered by their paired rat. Yoked rats received the same number of training sessions as paired rats, but because lever presses did not result in reinforcer delivery, they occurred only infrequently. Similarly, yoked rats received the same number of "extinction" sessions as their paired rats, in which both cocaine- and saline-yoked subjects received saline infusions in the same pattern as their paired self-administering subjects. The selfadministering rats to which others were cocaine yoked were chosen so that the mean cocaine intake of cocaine-yoked rats would be the same as the mean cocaine intake of all of the self-administering rats ( 20.5 vs 20.25 $\mathrm{mg} / \mathrm{kg}$ per $2 \mathrm{hr}$ session).

Reinstatement testing and microdialysis procedure. Microdialysis probes were constructed with inlet and outlet tubing (made of fused silica) inserted into a semipermeable membrane with $2 \mathrm{~mm}$ of active length. On the night before reinstatement testing, microdialysis probes were inserted into the NAcore, with the active membrane beginning $2 \mathrm{~mm}$ beyond the end of the guide cannula. Subjects were then housed in the operant chambers, in which they were given their daily ration of food and ad libitum access to water. On the following morning, dialysis buffer (5 mм glucose, $2.5 \mathrm{~mm} \mathrm{KCl,} 140 \mathrm{~mm} \mathrm{NaCl}, 1.4 \mathrm{~mm} \mathrm{CaCl}_{2}, 1.2 \mathrm{~mm} \mathrm{MgCl}_{2}$, and $0.15 \%$ PBS, pH 7.4) was perfused through the probe $(2 \mu \mathrm{l} / \mathrm{min})$ for 2 $\mathrm{hr}$, after which, $2 \mathrm{hr}$ of baseline samples were collected at $10 \mathrm{~min}$ intervals. All samples were collected into $10 \mu \mathrm{l}$ of mobile phase (150 mm sodium dihydrogen phosphate monobasic, $4.76 \mathrm{~mm}$ citric acid, $3 \mathrm{~mm}$ sodium dodecyl sulfate, $50 \mu \mathrm{M}$ EDTA, 10\% methanol v/v, and 15\% acetonitirle $\mathrm{v} / \mathrm{v}, \mathrm{pH}$ 5.6) to prevent oxidation of dopamine. Samples were then stored at $-80 \mathrm{C}$ for later analysis of dopamine and glutamate content.

After the $2 \mathrm{hr}$ baseline sampling, subjects were tested for their propensity to reinstate drug-seeking behavior after a challenge injection of cocaine $(10 \mathrm{mg} / \mathrm{kg}$, i.p., in a volume of $1 \mathrm{ml} / \mathrm{kg}$ bodyweight $)$ or saline $(0.9 \%$ in a volume of $1 \mathrm{ml} / \mathrm{kg}$ bodyweight). Immediately preceding systemic cocaine or saline challenge, some subjects also received bilateral microinfusion of saline or a combination of the $\mathrm{GABA}_{\mathrm{B}}$ agonist baclofen and the $\mathrm{GABA}_{\mathrm{A}}$ agonist muscimol $(\mathrm{B} / \mathrm{M})(0.3$ and $0.03 \mathrm{nmol}$, respectively) into the dorsal prefrontal cortex. The GABA agonist drugs were used to hyperpolarize the PFCd and produce a reversible inactivation of the area. For microinjections, obdurators were removed and bilateral infusion cannulas were inserted to extend $1 \mathrm{~mm}$ beyond the tip of the guide cannula. All infusions were made in a volume of $0.3 \mu \mathrm{l}$ over $60 \mathrm{sec}$. Microinfusion cannulas were left in place for $90 \mathrm{sec}$ after injection to allow time for diffusion. Obdurators were then replaced, an intraperitoneal injection of cocaine or saline was given, and animals were returned to the self-administration chambers for a $2 \mathrm{hr}$ reinstatement test. During reinstatement testing, active lever presses were counted but resulted in saline, not cocaine, delivery. Ten minute microdialysis samples were col- 

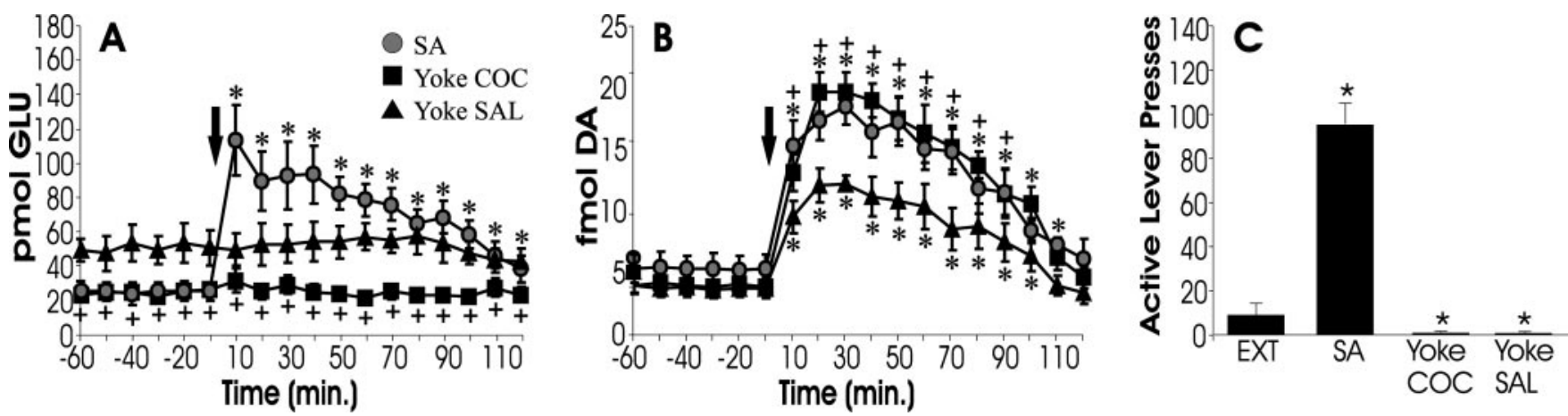

Figure 1. Cocaine-induced reinstatement responding is associated with a rise in accumbal glutamate rather than dopamine. $A$ and $B$ depict extracellular levels of glutamate $(A)$ and dopamine $(B)$ within the nucleus accumbens during cocaine-induced reinstatement testing. This figure depicts data from rats that passively received either cocaine (Yoke COC; $n=7)$ or saline (Yoke SAL; $n=$ 7) in the same temporal pattern that self-administering subjects $(S A ; n=6)$ lever pressed to receive cocaine infusions. Animals that received chronic cocaine displayed decreased basal levels of glutamate $(A ; S A$ and $Y o k e C O C)$ and increased responsivity of dopamine after cocaine challenge ( $B$; time 0 min). All groups showed a reliable increase in extracellular dopamine after $C O C$ challenge; however, only SA subjects showed a reliable increase in glutamate. Thus, glutamate levels are most closely related to lever pressing (C). Extinction responding (EXT) is shown for comparison. ${ }^{*} p<$ 0.05 indicates a significant difference from baseline (before $\mathrm{CO}$ challenge) or EXT; $+p<0.05$ indicates a significant difference from yoked SAL control subjects.

lected across the $2 \mathrm{hr}$ test session, and then subjects were disconnected and returned to their home cages.

Motor control. Subjects in the motor control experiment were trained using the same procedures described above for self-administering animals. However, during reinstatement testing, the levers were not extended into the chambers, thus no lever pressing occurred.

Food reinstatement. Food reinstatement subjects were trained in a manner parallel to cocaine self-administering rats. They were trained to lever press on an FR-1 schedule of reinforcement (each reinforcement consisting of a single $45 \mathrm{mg}$ Noyes food pellet) in daily $2 \mathrm{hr}$ sessions. Once stable responding was achieved, the schedule of reinforcement was increased to FR-2 and then to FR-5. Subjects remained in maintenance until lever pressing stabilized $(<10 \%$ variation across 3 consecutive days). Subjects then entered behavioral extinction, in which lever pressing no longer resulted in food delivery. Once lever presses fell to $<10 \%$ of maintenance levels across 3 consecutive days, rats were tested for their propensity to reinstate responding for noncontingent food delivery. The session started when the levers extended into the chamber and the house light illuminated. Subjects received two pellets immediately on the initiation and an additional 10 pellets at $2 \mathrm{~min}$ intervals for the first $20 \mathrm{~min}$ of the reinstatement session. Lever presses never resulted in food delivery.

Quantification of dopamine and glutamate. Before analysis, samples were thawed and divided, so they could be used to measure levels of both dopamine and glutamate. Of the $30 \mu \mathrm{l}$ in each sample (20 $\mu$ l of diastylate and $10 \mu \mathrm{l}$ mobile phase), $10 \mu \mathrm{l}$ was used for quantification of glutamate and $20 \mu \mathrm{l}$ was used for quantification of dopamine. For dopamine analysis, samples were placed in an ESA (Chelmsford, MA) model 540 autosampler connected to an HPLC system with electrochemical detection. Separation was achieved by pumping the samples through a $15 \mathrm{~cm} \mathrm{C} C_{18}$ reversed-phase column (ESA), and then samples were reduced-oxidized using coulometric detection. Three electrodes were used: a guard cell $(+400 \mathrm{mV})$, a reduction analytical electrode $(-150 \mathrm{mV})$, and an oxidation analytical electrode $(+250 \mathrm{mV})$. Peaks were recorded, and the area under the curve was measured by a computer running ESA Chromatography Data System. These values were normalized by comparison with an internal standard curve for isoproteronol and quantified by comparison with an external standard curve.

Concentration of glutamate in the samples was determined using HPLC with fluorometric detection. Samples were loaded by an autosampler (Gilson Medical Electric, Middleton, WI) that performed a precolumn derivitization with $o$-pthalaldehyde. Amino acids were then separated with a reversed-phase $\mathrm{C}_{18}(15 \mathrm{~cm})$ column. Glutamate was detected using a fluorescence spectrophotometer (Linear Fluor LC 305; ESA) using an excitation wavelength of $336 \mathrm{~nm}$ and an emission wavelength of $440 \mathrm{~nm}$. A chart recorder recorded peaks, and peak heights were measured. These values were normalized by comparison with an internal standard curve for homoserine and quantified by comparison with an external standard curve.
Histology and statistics. After reinstatement testing, subjects were overdosed with pentobarbital anesthesia ( $100 \mathrm{mg} / \mathrm{kg}$, i.p.) and then perfused transcardially with $0.9 \%$ physiological saline, followed by $10 \%$ Formalin. Brains were stored in Formalin for at least $24 \mathrm{hr}$ before being sectioned. Brains were blocked and sliced in coronal sections (50 $\mu \mathrm{m}$ thick) through the prefrontal cortex and nucleus accumbens to examine placement of both dialysis and microinfusion cannulas. Sections were mounted on gel-coated slides, stained with cresyl violet, and examined for cannula placement by an individual unaware of each subject's behavior. The data were statistically evaluated using a one-way or two-way ANOVA with repeated measures across time and between-subjects analyses across conditions. Post hoc comparisons between individual treatments were made using a Tukey's test.

\section{Results}

Cocaine-induced reinstatement is associated with elevations in nucleus accumbens glutamate but not dopamine

Figure 1 depicts levels of extracellular glutamate $(A)$ and dopamine $(B)$ measured in the nucleus accumbens during reinstatement testing for three groups of animals: those with previous experience self-administering cocaine or those that received passive infusions of cocaine (yoked cocaine) or saline (yoked saline) in the same pattern as self-administering animals. Only animals that had previously self-administered cocaine showed behavioral reinstatement (Fig. 1C) after cocaine challenge and were the only subjects to display increased extracellular glutamate within the accumbens (Fig. $1 A$ ). In contrast, all animals showed an increase in extracellular dopamine after cocaine challenge (Fig. $1 B$ ). These data suggest that increased levels of accumbens glutamate are specifically associated with reinstatement, whereas extracellular dopamine is not.

Consistent with previous studies, subjects that had received either self-administered or yoked cocaine infusions (Fig. 1, SA and Yoke COC) showed reduced basal glutamate levels (Fig. 1 A) and sensitized dopamine increases after cocaine challenge (Fig. $1 B)$ compared with yoked saline controls.

Inactivation of the dorsal prefrontal cortex blocks cocaineinduced reinstatement and rise in extracellular glutamate but does not affect dopamine

To assess the contribution of prefrontal cortical glutamatergic inputs to the accumbens in the reinstatement-associated rise in extracellular glutamate, the PFCd (for anterior cingulate and prelimbic cortex, see Fig. $6 \mathrm{~B}$ ) was reversibly inactivated with GABA agonists immediately preceding reinstatement testing. Rats re- 

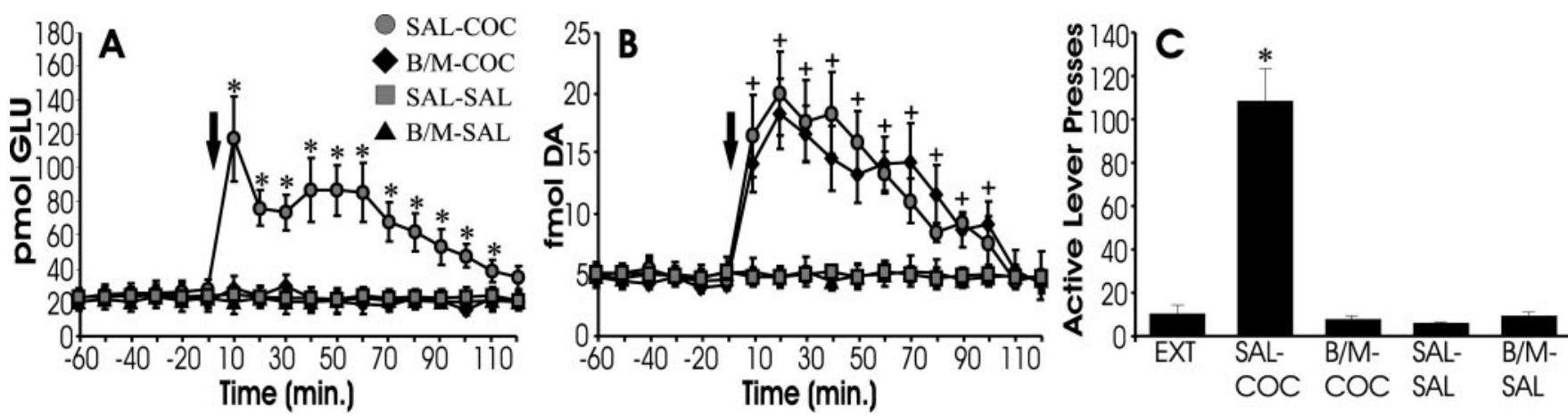

Figure 2. Inactivation of the dorsal prefrontal cortex blocks cocaine-induced reinstatement and the associated rise in extracellular glutamate. Extracellular levels of glutamate $(A)$ and dopamine $(B)$ were measured during reinstatement testing. Subjects received microinfusions of either SAL or B/M into the dorsal prefrontal cortex, followed by systemic (intraperitoneal) infusions of either $C O C$ or SAL at time 0 min. Thus, there were four treatment conditions (SAL-COC, $n=6 ; \mathrm{B} / \mathrm{M}-\mathrm{COC}, n=6 ; \mathrm{SAL}-\mathrm{SAL}, n=5 ; \mathrm{B} / \mathrm{M}-\mathrm{SAL}, n=5)$, with the intracranial treatment indicated first and the systemic treatment second. ( shows responding on the active lever during the $2 \mathrm{hr}$ test for reinstatement and, for comparison, shows responding during extinction conditions (EXT). Challenge with systemic SAL (SAL-SAL or B/M-SAL) did not elicit reinstatement or a rise in extracellular levels of glutamate or dopamine within the NAcore. In contrast, challenge with systemic COC elicited both renewed responding on the active lever as well as increases in extracellular levels of glutamate and dopamine within the NAcore. Inactivation of the PFCd with baclofen and muscimol before COC challenge blocked both the rise in extracellular glutamate and behavioral reinstatement but left the rise in NAcore dopamine unaffected (compare SAL-COC with B/M-COC). ${ }^{*} p<0.05$ indicates a significant difference from baseline (before $\mathrm{COC}$ challenge) or EXT; $+p<0.05$ indicates a significant difference from SAL control subjects.

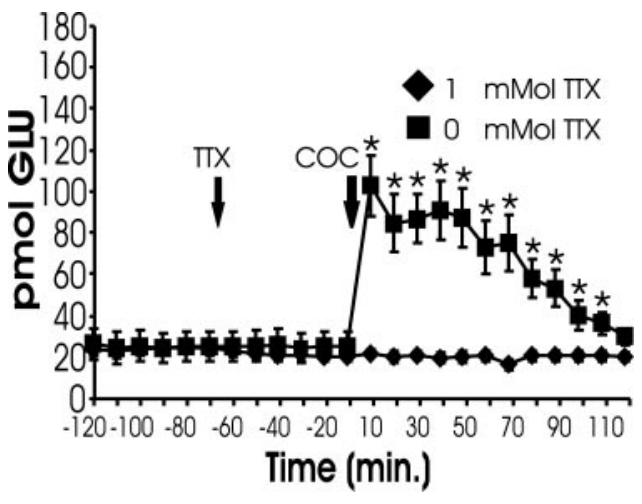

Figure 3. The reinstatement-associated increase in accumbal glutamate is activity dependent. One hour before cocaine challenge, TTX ( 0 or $1 \mu \mathrm{m} ; n=6$ per group) was advanced through the dialysis probe. Subjects pretreated with $0 \mu \mathrm{m}$ TTX showed a reliable increase in extracellular glutamate after $\mathrm{COC}$ challenge. This increase was blocked by $1 \mu \mathrm{m}$ TTX. ${ }^{*} p<0.05$ indicates a reliable increase from pre-cocaine baseline.

ceived microinfusions of the $\mathrm{GABA}_{\mathrm{B}}$ agonist baclofen and the $\mathrm{GABA}_{\mathrm{A}}$ agonist muscimol $(0.3$ and $0.03 \mathrm{nmol}$, respectively) or SAL into the PFCd before systemic challenge with COC or SAL. Thus, there were four treatment conditions: SAL-COC, B/MCOC, SAL-SAL, and B/M-SAL. As seen in Figure $2 C$, systemic COC (SAL-COC), but not SAL (SAL-SAL and B/M-SAL), elicited robust reinstatement responding on the previously drug-paired lever, and this responding was blocked by inactivating the PFCd with baclofen and muscimol (B/M-COC). Figure $2 \mathrm{~A}$ shows that the extracellular levels of glutamate within the NAcore paralleled behavioral responding because the increase in glutamate associated with behavioral responding in the SAL-COC group was abolished after inactivation of the PFCd (B/M-COC group). In contrast, the extracellular levels of dopamine did not correspond with behavior. COC challenge produced increases in extracellular dopamine that were resistant to inactivation of the PFCd (Fig. 2B).

Elevations in extracellular glutamate that underlie cocaineinduced reinstatement depend on neuronal activation Because the basal levels of extracellular glutamate levels depend primarily on nonsynaptic mechanisms (Baker et al., 2002), the

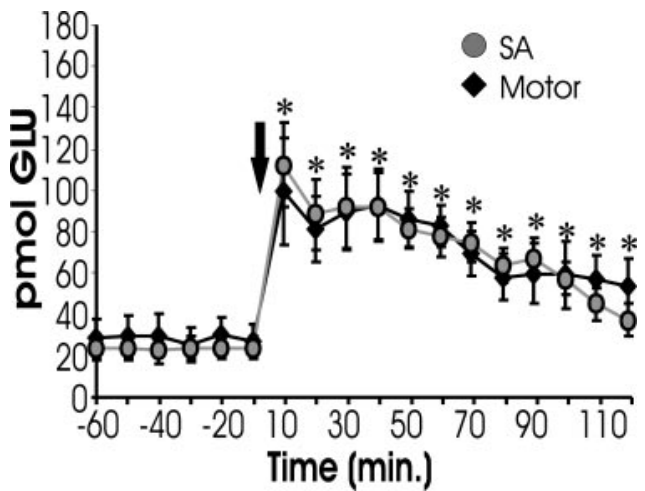

Figure 4. Cocaine-induced glutamate is not a byproduct of lever pressing. This figure shows extracellular glutamate levels measured from the NA of rats that were trained to lever press for cocaine and had their lever pressing extinguished (just like other self-administering subjects). However, the levers were not extended during reinstatement testing. After $\mathrm{COC}$ challenge, these subjects (Motor; $n=7$ ) displayed increased levels of glutamate within the NAcore comparable with increases shown by animals allowed to lever press during reinstatement $(S A$, from Fig. 1), suggesting that the rise in glutamate is not a consequence of behavioral responding.

contribution of action potential-dependent glutamate release to the reinstatement-associated rise in glutamate within the NAcore was assessed by perfusing the voltage-gated sodium channel antagonist tetrodotoxin (TTX) through the dialysis probe before cocaine challenge. Figure 3 shows that blocking voltage-gated sodium channels prevented the cocaine-induced rise in glutamate levels. As was reported previously (Timmerman and Westerink, 1997), TTX had no significant effect on basal levels of extracellular glutamate. Blockade of the cocaine-primed rise in extracellular glutamate by both TTX and inactivation of the PFCd strongly indicates that the elevation in glutamate underlying cocaine-induced reinstatement arises from activation of the glutamatergic projection from the PFCd to the NAcore.

\section{Elevated glutamate is not caused by operant responding}

It was possible that the observed glutamate release could be the result of, rather than the cause of, reinstatement (i.e., it was possible lever pressing caused the glutamate release instead of glutamate release leading to responding). To evaluate this possibility, animals were trained to self-administer cocaine and then under- 

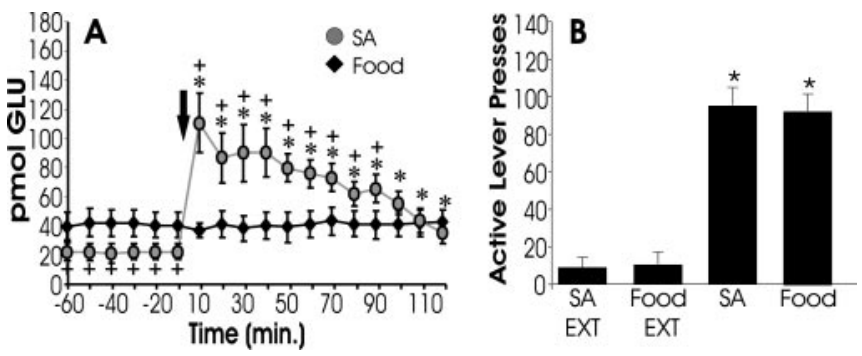

Figure 5. Food reinstatement is not associated with an increase in accumbal glutamate. Some subjects were trained to lever press for food reinforcement ( $45 \mathrm{mg}$ food pellet) and then had their lever pressing extinguished. $A$ shows extracellular glutamate levels measured in the NAcore during reinstatement elicited by noncontingent food delivery. $B$ shows active lever presses during extinction (EXT) and reinstatement (FOOD; $n=7)$. Note that, despite responding on the active lever at rates comparable with $\mathrm{COC}$ subjects, food animals show no increase in glutamate levels during reinstatement. Data from cocaine animals ( $S A$, from Fig. 1) is shown for comparison.

went behavioral extinction. However, during reinstatement testing, the levers were not extended after the cocaine-priming injection. Thus, no lever pressing was permitted. As Figure 4 shows, there was no difference in the rise in extracellular glutamate between animals exhibiting lever pressing (SA, from Fig. $1 A$ ) and those not exhibiting lever pressing.

\section{Food-induced reinstatement does not depend on nucleus accumbens glutamate}

To assess the selectivity of the rise in glutamate for cocaineprimed reinstatement, a separate group of animals was trained to lever press for food reinforcement, and extracellular glutamate was measured in the nucleus accumbens during food-induced reinstatement. In animals trained to lever press for food reinforcement, noncontingent food delivery produced levels of lever pressing comparable with that elicited by the cocaine-priming injection (Fig. 5B). However, food-induced reinstatement did not provoke a rise in extracellular glutamate (Fig. $5 A$ ), suggesting that accumbens glutamate does not underlie renewed responding for natural reinforcement.

\section{Histology}

Figure 6 shows the placement of dialysis membranes in the nucleus accumbens $(A)$ and microinjection sites in the prefrontal cortex $(B)$. Dialysis membranes tended to span the length of the NAcore, clustered around the anterior commissure, but avoided the ventromedial aspects of the nucleus accumbens (i.e., the shell of the nucleus accumbens). Microinjection sites in the PFCd clustered at the border between the anterior cingulate and prelimbic cortices. All placements were determined using the atlas of Paxinos and Watson (1998).

\section{Discussion}

The present study demonstrates that cocaine-induced reinstatement of drug-seeking behavior is initiated by increased glutamate transmission in the projection from the prefrontal cortex. Animals that had previously self-administered cocaine (SA) showed a rise in extracellular glutamate during cocaine-induced reinstatement responding that was blocked by inactivation of the dorsal prefrontal cortex. In contrast, there was no clear association between increased dopamine transmission and whether or not a subject engaged in renewed drug-seeking behavior (i.e., lever pressing). The fact that the cocaine prime did not alter glutamate in either yoked control group demonstrates that the increase in glutamate, unlike increased dopamine, is not an obligatory pharmacological effect of acute or repeated cocaine administration. Similarly, the fact that food-induced reinstatement of food-seeking behavior is not accompanied by an increase in extracellular glutamate within the accumbens suggests that the rise is not common to renewed responding for natural reinforcers. Moreover, the release of glutamate in response to a cocaine prime does not depend on execution of lever pressing, because when the levers were removed, the cocaine prime still elevated glutamate transmission in the subjects trained to self-administer cocaine.

Given the treatment conditions outlined above in which a cocaine-priming injection elicits reinstatement and a concurrent increase in extracellular glutamate, it appears that the glutamate may be involved in initiating the behavioral response. The relative importance of glutamate transmission is also indicated by the fact that the administration of AMPA glutamate receptor antag-
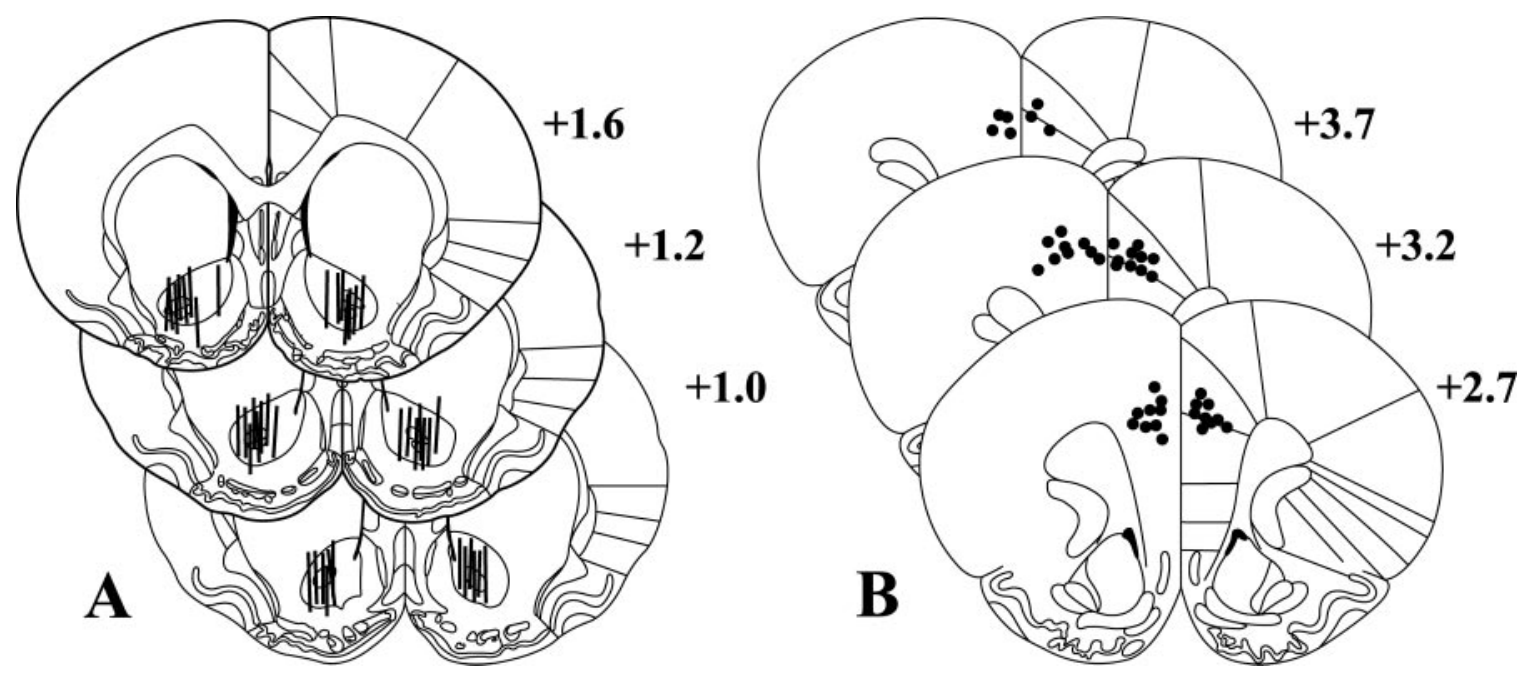

Figure 6. Histology. This figure depicts the placement of microdialysis membranes $(A)$ within the nucleus accumbens core and microinfusion sites within the dorsal prefrontal cortex $(B)$ based on the atlas of Paxinos and Watson (1998). For clarity, placements are only shown for subjects whose data are shown in Figures 1 and 2, but placements for all other subjects fall within the depicted range. Numbers indicate distance from bregma in the anteroposterior plane. 
onists into the NAcore blocked cocaine-primed reinstatement, whereas antagonizing $D_{1} / D_{2}$ dopamine receptors was without effect (Cornish and Kalivas, 2000; McFarland and Kalivas, 2001). Similarly, cued drug seeking maintained by a second-order schedule of cocaine reinforcement has been shown to be blocked by AMPA receptor antagonist administration into the core (not the shell) of the nucleus accumbens (Di Ciano and Everitt, 2001), raising the possibility that nucleus accumbens glutamate transmission might also be important for the behavioral effects of drug-paired cues. Such a notion is consistent with the finding that exposure to cocaine-paired cues elicits an increase in extracellular glutamate within the nucleus accumbens that is associated with the expression of conditioned locomotion (Hotsenpiller et al., 2001).

The fact that the prefrontal cortex is the source of the cocaineprimed increase in glutamate is consistent with imaging studies showing increased metabolic activity in the prefrontal cortex, especially the anterior cingulate cortex, during cue-primed craving in addicts (Grant et al., 1996; Childress et al., 1999; Kilts et al., 2001). Moreover, the activation of the anterior cingulate by cocaine or a cocaine-associated cue precedes the awareness of craving and may be more closely associated with mood states that initiate craving (Breiter et al., 1997; Volkow et al., 1999; Wexler et al., 2001). Analogous to studies in humans, animal studies demonstrate that there is an increase in immediate early gene expression in the anterior cingulate cortex associated with cocaine- or cue-primed reinstatement (Neisewander et al., 2000; Ciccocioppo et al., 2001; Thomas and Everitt, 2001). Moreover, Neisewander et al. (2000) noted that the anterior cingulate was the only brain region in which increased c-Fos expression was associated with both a drug and cue prime.

Pharmacological studies further establish the initiating role of the PFCd in precipitating drug-seeking behavior, because transient inhibition of the PFCd with GABA agonists or TTX prevent cocaine-, stress-, and cue-primed reinstatement (McFarland and Kalivas, 2001; Capriles et al., 2002; McLaughlin and See, 2003), and the microinjection of either cocaine or dopamine into the PFCd reinstates drug-seeking behavior (McFarland and Kalivas, 2001; Park et al., 2002). Moreover, reinstatement initiated by cocaine microinjection into the PFCd was blocked by inhibiting AMPA receptors in the nucleus accumbens, demonstrating involvement of the prefrontal-accumbens glutamatergic projection (Park et al., 2002). Finally, although blockade of dopamine receptors in the NAcore was ineffective, microinjection of the dopamine antagonist into the PFCd abolished cocaine-primed reinstatement (Cornish and Kalivas, 2000; McFarland and Kalivas, 2001).

Given the importance of increased glutamate release in the nucleus accumbens for the initiation of cocaine-primed reinstatement, it is surprising that repeated cocaine administration causes an enduring reduction in glutamate transmission in the nucleus accumbens. Thus, after repeated cocaine administration, there is a decrease in basal extracellular glutamate, especially when subjects have been trained to associate cocaine with environmental stimuli (Pierce et al., 1996; Bell et al., 2000; Hotsenpiller et al., 2001). In addition, after repeated cocaine, there is a reduction in signaling through group I and group II metabotropic glutamate receptors (Swanson et al., 2001; Xi et al., 2002). Furthermore, there is a reduction in electrophysiological sensitivity of AMPA glutamate receptors to electrical stimulation of the prefrontal cortex (Thomas et al., 2001), and an enhanced inhibitory effect of dopamine on excitatory AMPA currents (White et al., 1995; Beurrier and Malenka, 2002). However, the apparent tonic downregulation of presynaptic and postsynaptic glutamate transmission by repeated cocaine may contribute to the enhanced release and detection of glutamate after a cocainepriming injection. For example, basal levels of extracellular glutamate have been shown in vivo to provide tone on group II mGluR autoreceptors (Baker et al., 2002; Xi et al., 2002), and the cocaine-induced reduction in basal glutamate combined with desensitization of group II mGluRs would be expected to promote increased release of synaptic glutamate after activation of the prefrontal cortex.

In summary, the release of glutamate into the NAcore by a cocaine priming injection initiates reinstatement of drug-seeking behavior in rats trained to self-administer cocaine, and the glutamate arises from PFCd afferents to the accumbens. The fact that a similar release of glutamate was not elicited by a food prime in subjects trained to self-administer food poses the possibility that the cocaine-induced release of glutamate is indicative of a pathological change in addiction rather than a physiological response initiating reinstatement of behavior to obtain natural rewards. As such, pharmacological modulation of glutamate release may prove an effective target for selectively treating craving for drugs of abuse.

\section{References}

Baker DA, Xi Z-X, Shen H, Swanson CJ, Kalivas PW (2002) The origin and neuronal function of in vivo nonsynaptic glutamate. J Neurosci 22:9134-9141.

Bell K, Duffy P, Kalivas PW (2000) Context-specific enhancement of glutamate transmission by cocaine. Neuropsychopharmacology 23:335-344.

Beurrier C, Malenka RC (2002) Enhanced inhibition of synaptic transmission by dopamine in the nucleus accumbens during behavioral sensitization to cocaine. J Neurosci 22:5817-5822.

Breiter HC, Gollub RL, Weisskoff RM, Kennedy DN, Makris N, Berke JD, Goodman JM, Kantor HL, Gastfriend DR, Riorden JP, Mathew RT, Rosen BR, Hyman SE (1997) Acute effects of cocaine on human brain activity and emotion. Neuron 19:591-611.

Capriles N, Rodaros D, Sorge RE, Stewart J (2002) A role for the prefrontal cortex in stress- and cocaine-induced reinstatement of cocaine seeking in rats. Psychopharmacology (Berl), in press.

Childress AR, Mozley PD, McElgin W, Fitzgerald J, Reivich M, O'Brien CP (1999) Limbic activation during cue-induced cocaine craving. Am J Psychiatry 156:11-18.

Ciccocioppo R, Sanna PP, Weiss F (2001) Cocaine-predictive stimulus induces drug-seeking behavior and neural activation in limbic brain regions after multiple months of abstinence: reversal by $\mathrm{D}(1)$ antagonists. Proc Natl Acad Sci USA 98:1976-1981.

Cornish JL, Kalivas PW (2000) Glutamate transmission in the nucleus accumbens mediates relapse in cocaine addiction. J Neurosci 20:RC89(1-5).

Cornish JL, Duffy P, Kalivas PW (1999) A role for nucleus accumbens glutamate transmission in the relapse to cocaine-seeking behavior. Neuroscience 93:1359-1367.

De Vries TJ, Schoffelmeer ANM, Binnekade R, Vanderschuren LJMJ (1999) Dopaminergic mechanisms mediating the incentive to seek cocaine and heroin following long-term withdrawal of IV drug self-administration. Psychopharmacology 143:254-260.

De Vries TJ, Schoffelmeer AN, Binnekade R, Raaso H, Vanderschuren LJ (2002) Relapse to cocaine- and heroin-seeking behavior mediated by dopamine D2 receptors is time-dependent and associated with behavioral. Neuropsychopharmacology 26:18-26.

Di Ciano P, Everitt BJ (2001) Dissociable effects of antagonism of NMDA and AMPA/KA receptors in the nucleus accumbens core and shell on cocaine-seeking behavior. Neuropsychopharmacology 25:341-360.

Ettenberg A (1989) Dopamine, neuroleptics and reinforced behavior. Neurosci Biobehav Rev 13:105-111.

Fallon JH, Moore RY (1978) Catecholamine innervation of basal forebrain. IV. Topography of the dopamine projection to the basal forebrain and striatum. J Comp Neurol 180:545-580.

Gnegy ME (2000) $\mathrm{Ca}^{2+} /$ calmodulin signaling in NMDA-induced synaptic plasticity. Crit Rev Neurobiol 14:91-129. 
Grant S, London ED, Newlin DB, Villemagne VL, Liu X, Contoreggi C, Phillips RL, Kimes AS, Margolin A (1996) Activation of memory circuits during cue-elicited cocaine craving. Proc Natl Acad Sci USA 93:12040-12045.

Henry DJ, White FJ (1991) Repeated cocaine administration causes persistent enhancement of $D_{1}$ dopamine receptor sensitivity within the rat nucleus accumbens. J Pharmacol Exp Ther 258:882-890.

Hotsenpiller G, Giorgetti M, Wolf ME (2001) Alterations in behaviour and glutamate transmission following presentation of stimuli previously associated with cocaine exposure. Eur J Neurosci 14:1843-1855.

Kilts CD, Schweitzer JB, Quinn CK, Gross RE, Muhammad F, Hofmann J, Drexler K (2001) Neural activity related to drug craving in cocaine addiction. Arch Gen Psychiatry 58:334-341.

Koob G, Swerdlow N (1988) The functional output of the meslimbic dopamine system. Ann NY Acad Sci 537:216-227.

McFarland K, Kalivas PW (2001) The circuitry mediating cocaine-induced reinstatement of drug-seeking behavior. J Neurosci 21:8655-8663.

McLaughlin J, See R (2003) Reversible inactivation of the dorsomedial prefrontal cortex attenuates conditioned reinstatement of cocaine-seeking behavior in rats. Psychopharmacology, in press.

Neisewander JL, Baker DA, Fuchs RA, Tran-Nguyen LTL, Palmer A, Marshall JF (2000) Fos protein expression and cocaine seeking behavior in rats after exposure to a cocaine self-administration environment. Neuroscience 20:798-805.

Park WK, Bari AA, Jey AR, Anderson SM, Spealman RD, Rowlett JK, Pierce RC (2002) Cocaine administered into the medial prefrontal cortex reinstates cocaine-seeking behavior by increasing AMPA receptor-mediated glutamate transmission in the nucleus accumbens. J Neurosci 22:2916-2925.

Paxinos G, Watson C (1998) The rat brain in stereotaxic coordinates. New York: Academic.

Pierce RC, Kalivas PW (1997) Repeated cocaine modifies the mechanism by which amphetamine releases dopamine. J Neurosci 17:3254-3261.

Pierce RC, Bell K, Duffy P, Kalivas PW (1996) Repeated cocaine augments excitatory amino acid transmission in the nucleus accumbens only in rats having developed behavioral sensitization. J Neurosci 16:1550-1560.
Reid MS, Berger SP (1996) Evidence for sensitization of cocaine-induced nucleus accumbens glutamate release. NeuroReport 7:1325-1329.

Swanson CJ, Baker DA, Carson D, Worley PF, Kalivas PW (2001) Repeated cocaine administration attenuates group I metabotropic glutamate receptor-mediated glutamate release and behavioral activation: a potential role for Homer. J Neurosci 21:9043-9052.

Thomas KL, Everitt BJ (2001) Limbic-cortical-ventral striatal activation during retrieval of a discrete cocaine-associated stimulus: a cellular imaging study with gamma protein kinase C expression. J Neurosci 21: 2526-2535.

Thomas MJ, Beurrier C, Bonci A, Malenka RC (2001) Long-term depression in the nucleus accumbens: a neural correlate of behavioral sensitization to cocaine. Nat Neurosci 4:1217-1223.

Timmerman W, Westerink BH (1997) Brain microdialysis of GABA and glutamate: what does it signify? Synapse 27:242-261.

Volkow ND, Wang GJ, Fowler JS, Hitzemann R, Angrist B, Gatley SJ, Logan J, Ding YS, Pappas N (1999) Association of methylphenidate-induced craving with changes in right striato-orbitofrontal metabolism in cocaine abusers: implications in addiction. Am J Psychiatry 156:19-26.

Wexler BE, Gottschalk CH, Fulbright RK, Prohovnik I, Lacadie CM, Rounsaville BJ, Gore JC (2001) Functional magnetic resonance imaging of cocaine craving. Am J Psychiatry 158:86-95.

White SR, Harris GC, Imel KM, Wheaton MJ (1995) Inhibitory effects of dopamine and methylenedioxymethamphetamine (MDMA) on glutamate-evoked firing of nucleus accumbens and caudate/putamen cells are enhanced following cocaine self-administration. Brain Res 681: $167-176$

Xi ZX, Baker DA, Shen H, Carson DS, Kalivas PW (2002) Group II metabotropic glutamate receptors modulate extracellular glutamate in the nucleus accumbens. J Pharmacol Exp Ther 300:162-171.

Zhang XF, Cooper DC, White FJ (2002) Repeated cocaine treatment decreases whole-cell calcium current in rat nucleus accumbens neurons. J Pharmacol Exp Ther 301:1119-1125. 